\title{
BMJ Open \\ Listening to patients with cancer: using a literary-based research method to understand patient-focused care
}

\author{
Amanda Begley, ${ }^{1}$ Kathy Pritchard-Jones, ${ }^{1}$ Maurice Biriotti, ${ }^{2}$ Anna Kydd, ${ }^{2}$ \\ Tim Burdsey, ${ }^{1}$ Emma Townsley ${ }^{3}$
}

To cite: Begley A, PritchardJones $\mathrm{K}$, Biriotti M, et al. Listening to patients with cancer: using a literary-based research method to understand patient-focused care. BMJ Open 2014;4: e005550. doi:10.1136/ bmjopen-2014-005550

- Prepublication history for this paper is available online. To view these files please visit the journal online (http://dx.doi.org/10.1136/ bmjopen-2014-005550)

Received 28 April 2014 Revised 14 September 2014 Accepted 16 September 2014

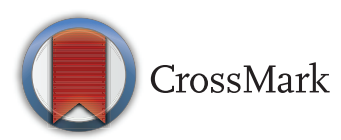

${ }^{1}$ UCLPartners, London, UK ${ }^{2}$ SHM London, London, UK ${ }^{3}$ National Hospital for Neurology \& Neurosurgery, London, UK

\section{Correspondence to}

Dr A Begley;

amanda.begley@uclpartners. com

\section{ABSTRACT}

Objective: In spite of considerable attention, patients diagnosed with cancer continue to report poor experiences of care. The root causes of this remain unclear. This exploratory study aimed to investigate new ways of understanding the experience of patients with cancer, using a literary-based research approach.

Design: Interviews were undertaken with four patients diagnosed with high-grade brain cancers at least 6 months from diagnosis and with people $(n=5)$ identified by the patients as important in their care pathway. Interview transcripts were analysed by humanities academics as pieces of literature, where each patient's story was told from more than one person's perspective. The academics then came together in a facilitated workshop to agree major themes within the patient experiences. The themes were presented at a patient and carer event involving 70 participants to test the validity of the insights.

Results: Insights into the key issues for patients with cancer could be grouped into six themes: accountability; identity; life context; time; language; rigour and emotion. Patients often held a different perspective to the traditionally held medical views of what constitutes good care. For example, patients did not see any conflict between a doctor having scientific rigour and portraying emotion.

Conclusions: One key feature of the approach was its comparative nature: patients often held different views from those traditionally held by physicians of what constitutes health and good outcomes. This revealed aspects that may be considered by healthcare professionals when designing improvements. Proposals for further testing are discussed, with a particular emphasis on the need for sensitivity to individual differences in experiences.

\section{INTRODUCTION}

All in all, please remember, patients are human beings, just like the staff, we have feelings and are trying to have as much of a life as possible. We sit there working out what out of our life dreams we can actually now expect to be able to do. What kind of a future can we plan now? We have families
Strengths and limitations of this study

- The humanities-based research approach did generate new insights into understanding patient experience.

- To test the feasibility and resources required to execute the study design in practice, the sample for this exploratory study was small and as such was not intended to produce generalisable implications for practice

- To make recommendations for practice, further research is needed.

that we love and want to protect, just like anyone, we walk away from appointments evaluating every word that was said to us and that affects us and those around us profoundly on a daily basis. Everything that is said to us means so much [patient with brain cancer]

Many countries are concerned by variation in survival and experience of care by patients with cancer. This has been most intensively studied in the UK, where there is a national programme aimed at improving survival rates to the level of the best seen in developed health economies, and a national annual survey of patient experience.

According to the England's 2012/2013 national cancer patient experience survey, the experience of patients with cancer is in many areas improving. ${ }^{1}$ However, there remains considerable scope for improvement and there is significant variation across tumour types and regions. Patients with rarer forms of cancer (eg, brain and central nervous system) generally report a significantly poorer experience of their treatment and care than patients with the four most common forms of cancer. On some questions these patients score 20-30 percentage points lower than patients with breast cancer, who report the best experience. There is considered to be a 'London effect' as 
patients treated within London hospitals report a less positive experience compared to hospitals elsewhere in England.

National patient experience surveys have been important in enabling national benchmarking, in tracking performance over time and also in highlighting variation. However, feedback suggests they have had limited impact in driving improvements in the quality of services locally. ${ }^{2}$ Therefore additional approaches to structured surveys are used to drive improvements in patient experience. Furthermore, a specific focus is warranted on further understanding those areas of cancer care where significantly poorer experience is consistently reported, namely, brain cancer and in the London region. This paper summarises an exploratory study adapting the 'narrative medicine' approach.

\section{Narrative medicine}

The use of illness narratives in clinical medicine has been highlighted since the 1970s after social scientists began to take note of the difference between illness and disease. It is not possible in this brief introduction to do justice to the decades of 'insight and wisdom' generated by researchers analysing the many 'nuanced meanings of narrative' $(\mathrm{px}) .{ }^{3}$ Here, the focus is on the potential of using stories to improve healthcare design and delivery.

Illness narratives serve multiple purposes for patients. In relation to experience of the healthcare system, stories are considered to give "voice to suffering in a way that lies outside of the domain of the biomedical voice' (ref. 4, p.49) and to restore agency in a system in which patients have been 'increasingly rendered passive. ${ }^{5}$ In Frank's reflection on 'why illness needs stories', he describes them as allowing patients to 'reclaim their experience from others' narrative representations, especially official medical texts ... to which patients are granted access only under the most grudging conditions' (ref. 6, p.189). In this sense, narratives can empower people, helping them 'find a voice' within the healthcare system.

In relation to the potential for improving healthcare delivery, storytelling has been long understood by social scientists, and increasingly within the healthcare setting, as 'a powerful way of introducing the patient's perspective into the research agenda', (p.17) and making patients the focal point of the clinical experience. ${ }^{7}$ The employment of narrative medicine has been encouraged 'to recognize, interpret, and be moved to action by the predicaments of others' ${ }^{8}$ and to uncover new diagnostic and therapeutic options. ${ }^{7} 9$ The proliferation of biographical and autobiographical accounts of chronic illness has helped to deliver and consolidate these new patient-centred perspectives. ${ }^{10-13}$

However, illness narratives take many forms and serve many functions, they are 'constantly changing and being renegotiated' (ref. 4, p.61) and are argued to require ongoing interpretation in order to yield useful insights for clinical practice. ${ }^{4}{ }^{14}$ Furthermore, there remains a strong sense that the institutional practices of the present healthcare system afford only limited opportunities for patients to 'share their personal experience of illness' (ref. 7, p.17) and 'render such holism untenable' (ref. 14, p.144). This is argued to be because 'the focus of biomedical treatment is the disease, the 'personal integrity' or 'wholeness' of the presenting patient is not given primacy by many health professionals' (ref. 7, p.11).

In recent years, new approaches to understanding patients' perspectives and informing service redesign have been applied, as an alternative to the standard survey techniques. Patient stories are used to provoke discussion and debate among healthcare professionals around quality issues (http://www.patientvoices.org.uk) and Experience-Based Design involves patients in redesigning services based on their actual experiences of health services. ${ }^{15}$ However, miscommunication and misunderstanding between clinicians and patients still exist, leading to unsatisfactory experiences for patients and their families, as well as for professionals providing care.

By using comparative literary techniques using multiple narratives of patient care, this study identifies that the patient pathway is a lived experience, not only for patients but also carers, relatives, other advocates and health professionals. It was hypothesised that having patient and clinician accounts read as pieces of literature, as if they were authored texts by humanities experts, may yield new insights into the patient experience. A better understanding was sought of the language used by different participants, the different 'stories' told to describe their experience of giving or receiving care and the patients' journey through the healthcare system. Points of similarity and difference were also identified in order to explore the challenges and the possibilities of establishing 'common ground' between patients and National Health Service (NHS) professionals.

\section{EXPLORATORY STUDY DESIGN}

A Research Group was established to design and deliver an innovative approach to understanding and addressing poor patient experience for those diagnosed with cancer. The Group included the lead nurse specialist, two researchers and the research supervisor. The Group decided to test the approach within the brain cancer pathway, based on the lower national patient experience scores across a number of measures for this tumour type. ${ }^{1}$ The Group secured Research and Development and Ethics approval to undertake the study.

\section{Sampling and recruitment}

The study was undertaken over a 3-month period within the UK's largest dedicated neurological and neurosurgical hospital.

The Clinical Nurse Specialist reviewing the patients at hospital identified four patients who met the inclusion criteria, namely, diagnosed with a high-grade glioma and 
who were at least 6 months from diagnosis. This ensured that the patients had experienced the usual therapeutic elements of the brain tumour pathway, namely, surgery, chemotherapy and radiotherapy, and had time to recover from the acute toxicities. In addition to the presence of a diagnosed brain tumour, respondents were recruited on the basis that they had the mental capacity to consent to participate in the research study, were able to speak English and were capable of participating in an interview.

At the beginning of the interviews, patients were invited to identify for interview up to five additional people they considered to be significant to their experience of care. This was not a requirement to their participation in the study. Where patients wanted to identify others, they were asked to consider identifying clinicians. One aim of the study was to explore comparisons between different perspectives on the experiences of a patient.

The researchers gave their time in kind. Therefore, it was decided to limit the patient cohort in this exploratory phase to a sample of up to five patients, which could have generated 25 transcripts (five patients, each with five significant others).

\section{Interviews}

A single interview was conducted with each interviewee by a member of the research team. In the case of the patients, the interviews took place on the day of the patient's routine hospital appointment. The interviews lasted approximately $1 \mathrm{~h}$, and were semistructured and open-ended. The emphasis of the interviews was on the patient telling their story of living with brain cancer from whenever they wanted to start their story and about any part of their experience, with minimal prompting from the researcher. The researcher provided a set of creative materials including a range of images and pens that could be used to tell their story if they so wished.

No information disclosed in the course of the interviews was shared with any of the additional interviewees, and vice versa.

Each interview was followed by a debriefing session involving the interviewer and participant. All participants received a transcript of their interview within 2 weeks of the interview and asked to check it for accuracy.

\section{Analysis}

The anonymised interview transcripts were passed securely to three humanities academics (Kord, Stougaard-Nielson, Kapila) who analysed the transcripts individually from a range of critical angles: linguistic, philosophical and especially literary. The academics were made aware of the interview process-that it was semistructured and open-ended, giving patients the opportunity to start their story from where they wanted to. No additional information or background was provided to the academics in respect to the interviewees or interview. The academics were not directed as to how to read or interpret the transcripts, beyond an instruction to treat them as literature, as though they had been 'authored'.

The three academics then came together in a half-day facilitated workshop to develop initial insights in to the patient experiences. In the facilitated workshop a patient transcript was selected and the facilitator asked each academic to give their analysis of the particular text from their own discipline. The facilitator then led a discussion after each round of transcripts had been analysed to identify and draw out key themes. At the end of the workshop there was a discussion to draw out the major themes.

The findings were then presented by a member of the research team at a patient and carer event involving 70 participants. The aim was to test the validity of the insights with a larger cohort. Following the presentation, attendees participated in round table discussions on each of the insights. Participants were asked whether each insight resonated or not, and whether the insights were correctly interpreted. The table discussions were summarised and fed back to participants to check for accuracy.

\section{RESULTS}

\section{Participants}

During the 3 months research timeframe, four patients met the inclusion criteria. All four consented to participate. The four patients identified five 'significant others' (two relatives, two consultants and one general practitioner) as being significant to their experience of care. Giving a total of nine interviewees.

Three of the four patients were male and the age range was 36-64 years. One patient did not disclose his age but was considered by the interviewer to be in his late 30s. The patient profiles are summarised in table 1 .

\section{Findings}

Six insights were identified at the academic workshop as key issues for patients with brain cancer: accountability; identity; life context; time; language; rigour and emotion. The insights were confirmed at the patient and care event to be important contributors to patient experience. At the event, the need for careful consideration of individual differences in experiences was also highlighted. For the themes of accountability, life context and

\begin{tabular}{lll} 
Table 1 & Patient profiles & \\
\hline Patient & Gender & Age (years) \\
\hline P1 & Male & 36 \\
P2 & Female & 64 \\
P3 & Male & 48 \\
P4 & Male & Undisclosed \\
\hline
\end{tabular}


Table 2 Selected quotations from interview transcripts for each insight

\begin{abstract}
Accountability
Patient quote: "She is not just my wife. She is my driver, she is a cook, she is the mother of my children. ..The closest person is your wife or your husband. After that coming nurse, doctor. But due to my operation, the type of illness I had, I put Dr in the first place, because she, look after... when I need a massage, at that hospital, they give me some massage ... Macmillan help me to come, change my toilet and shower room, put a special chair in there, which the government cannot do". (P3)
\end{abstract}

\section{Life context}

Patient quote: "I think it was actually when they realised what was going on in the brain itself. I did feel it was all a bit of a whirlwind, but because the path was already laid out for me I didn't feel anxious in going down it. The thing I really struggled with wasn't necessarily medical, it was my family and the responsibility I felt for dragging them through this". (P1)

\section{Language}

Patient quote: "In terms of language the doctors use when talking to patients, I think it's not what they say, it is HOW they say it.(Patient at patient workshop)"

Physician quote: 'You can't just go into there and say 'Ok well this is how it is' ) so what we try and do is enlighten them as to what our stance might be, what they can expect from us in terms of information, sort of, scan results or how things are going". But, I also say to them, "Look, we will be guided by you, because not everybody wants all this information and we will be very much guided by the questions that you ask us." (Clinician)

\section{Identity}

Patient quote: 'I'm a disabled person. I'm registered and I have a car. But I don't see myself as a disabled person [...] you have to fight against your disease and against your illness". (P3)

\section{Time}

Patient quote: "After it happened, we were like completely living in the moment like even things looked differently physically. You know, you were noticing things that you didn't notice before, everything we were doing was just about the moment it wasn't about what was going to happen tomorrow or next year". (P1)

\section{Rigour and emotion}

Patient quote: "Very frequently doctors who seek excellence have difficulty with empathy.(patient at workshop)"

Physician quote: "One of the most difficult things that I have to deal with, particularly with these low grade tumours is the idea that actually, probably the best thing for them is to not to do anything about their tumour at all. What we would call 'watch and wait'. You have to say well we're not going gonna do anything about it. That is a really difficult message to get across and to explain why." (Clinician) language there were differences in emphasis and preference. The six insights and individual differences are described in the sections below. Selected quotations for each insight are provided in table 2.

\section{Accountability}

A number of apparent contradictions were identified within the patient narratives. Patients reported at different junctures in their stories sometimes wanting to retain personal accountability and sometimes wanting others to take responsibility on their behalf. One patient described how having clinicians taking charge often inspired him to also take more control. It did not render him a passive recipient. The literary analysis revealed that by contrast the clinicians were at pains to distinguish clearly between different kinds or levels of accountability or responsibility, and the boundaries between them. When read as literature the patients' stories highlight that for them accountability is not an 'either/or' but a complex concept that includes patient, physician, family, environment and history. The complex nature of accountability has been well documented. ${ }^{16} 17$ Furthermore, the finding of individual preferences highlighted in other studies, ${ }^{16}$ was confirmed at the patient and carer event, where participants emphasised individual preferences around accountability, and how these might change along a pathway of care.

\section{Identity}

The academics compared the patient stories to 19th Century literature, since they portrayed strong central characters engaged in a heroic struggle against an intruding or alienating world. Patients-as the central character in their own stories-described how they maintained a sense of dignity in the face of intrusion from cancer. The experience of loss of self is well documented, ${ }^{10-13}$ and there is evidence to suggest that patients look outside of mainstream treatment 'in order to preserve a sense of personal integrity' (ref. 7, p.12). The comparative literary interpretation moved beyond patients wanting to be treated as a whole person, rather than a condition or collection of symptoms. Patients reported feeling a loss of identity and uniqueness as an individual within a vast healthcare system at exactly the time at which their own existence and their roles in their life story became most significant. While patients might feel like the main protagonists outside the hospital environment, the clinical setting introduces a parenthesis in their story; in this context it is the doctor and not the patient who is the central character. 


\section{Life context}

The academics noted that patient stories did not typically start with, or dwell on, the diagnosis of cancer. Their driving force seemed to be in the past, 'before it all started', or in the future. The stories were concerned with making sense of everything that had happened and giving meaning to what was to come. They were concerned with the question: 'How do I want to live?'

The patient narratives conveyed a powerful sense of purpose and a drive for personal and specific goals, not just the management of a condition. As such the need to understand the personal narratives of individuals to improve experience was highlighted. This contrasts with the prevailing approach of the current healthcare system, which measures clinical outcomes or progress along a pathway, rather than achievement of an individual's personal goals. While Hyden argues that 'the patient seeks to find an explanation for and to understand his or her illness in order to find an ending for the illness narrative' (ref. 4, p.63), the literary interpretation identified that patients start and end their narrative within their life context. The focus of patients is not necessarily to extend their narrative, but rather to fulfil it according to their own definition.

\section{Time}

Patients told their stories in whichever structure made best sense of their experience, rather than in a framework that paid attention to historical sequence or the objective time of the institution. ${ }^{18}$ Much like the clash that has been identified in the clinical encounter between the 'voice of medicine' and the 'voice of the life world', ${ }^{19}$ the accounts of patients and clinicians attitudes to time are distinct. 'Patient time'-time as experienced and understood by patients-was more like literature than science: a minute might be a chapter; a year a single sentence. By contrast, clinicians spoke of time as something to be quantified, managed and measured. When patient time collides with institutional time, the effect can be jarring for the patient.

\section{Language}

Clinicians talked about sustaining a dual languagetranslating complicated technical words for patients and carers. When patients used medical language in their narratives, they did so with a sense of establishing control and mastery over their condition. Conversely, their stories of not understanding clinicians were about losing control, and confusion, rather than simple meaning of words. For these patients, the opposition between patient language and complex language was a false one. The relationship between naming and control is a long-established literary device. At the patient and carer event, participants confirmed language as an important component of patient experience. However, there were a range of perspectives on this. Some participants emphasised the need for more accessible, nontechnical language, while many described mastering medical language as a tool for gaining control over their future.

\section{Rigour and emotion}

In the patient stories, there was no opposition or contradiction between being rigorous and displaying emotion. This is also true in literature. The stories mirrored literary rather than scientific accounts in which logic and emotion can coexist. The stronger the emotional content of the stories, the stronger was the drive for rigour patients described. The better the rigour around patients, the better they were able to cope with their emotions. Set against these, the stories that clinicians told created a clear split: half story and half science. The doctors' need for dichotomy was in opposition to patient narratives in which rigour and emotion were intensified by one another. Clinicians' stories portrayed an NHS that is organised either for greater rigour or for greater emotional engagement and empathy. Within clinician's accounts, emotion was portrayed as being inimical to rigour.

\section{DISCUSSION}

\section{Insights in to the patient experience}

This study generated six insights into the experiences of four patients with brain cancer at a specific point within their treatment pathway, recounted from their own perspective and that of their carers and doctors. The six thematic conclusions were confirmed as highly relevant to patient experience at a workshop attended by 70 patients and carers. As an exploratory study, this was not intended to produce generalisable implications for practice, but rather to suggest a possible experimental paradigm for interpretation and analysis.

Individual differences within the insights were highlighted alongside patients' perspectives changing along the course of their care pathway. Sensitivity to individual differences was considered particularly important within three of the insights: language, life context and accountability. The relevance of individual differences to patient experience is particularly pertinent as health services internationally are striving for improved patient experience alongside greater efficiency and standardisation of protocols and processes. To make any recommendations for practice, further research is needed on the impact of individual differences on patient experience.

\section{The research approach}

One aim of this exploratory study was to test the utility of a new approach to understanding patient experience and identifying recommendations for service delivery.

It is important to recognise the advantages and limitations of different approaches to understanding and improving patient experience. National surveys enable service level performance to be tracked over time and benchmarked, and to identify performance variation across services and sites. However, as surveys rely on 
standardisation, the researcher develops questions general enough to be minimally appropriate for all respondents. Therefore, what is most appropriate to individual respondents may be excluded.

This exploratory study sought to test a different approach to understanding the experiences of patients. Incorporating humanities academics in to this research moved the interpretation of the patient stories beyond the customary ways of thinking within the NHS.

As well as building on key findings already identified within the large sociological literature around illness narratives a multiperspective comparative literary approach provides an original way of interpreting patient experience; comparing and contrasting two narrative frames (from patient and clinician) has yielded new insights.

As the current research design was not intended to identify recommendations for service improvement, it is being adapted for future use. Further research is needed to determine whether the six identified themes are an exhaustive list of insights; the impact of each insight-singularly and collectively-on patient experience; and whether the insights are applicable to other tumour types and to other disease pathways. Further research is also needed to understand whether the misalignment between the perspectives of patients and professionals as to what is most important at each step in the brain cancer pathway might be a fundamental source of poor patient experience.

Acknowledgements The authors thank the interviewees for their time and openness, The Brain Tumour Charity for allowing us to validate the findings with attendees at their London information day and the National Hospital for Neurology and Neurosurgery for their cooperation and support. Without this the research would not have been possible. The authors are very grateful to the academics who took part in the analysis sessions for this work. In particular we would like to acknowledge the significant contributions made by Professor Susanne Kord, Professor in German in the University College London Department of German, Dr Jakob Stougaard-Nielsen Lecturer in Scandinavian Literature in the School of European Languages, Culture and Society at University College London and Dr Kriti Kapila Lecturer in Social Anthropology and Law at the Kings India Institute at Kings College London. And to Nigel Shardlow who contributed to all aspects of the research.

Contributors $A B$ supervised the research, contributed to the study design and analysis, drafted and revised the paper. She is guarantor. KP-J contributed to the study design, acted as advisor throughout the research process, revised the paper. MB designed the study and participated in the analysis. AK designed and supervised fieldwork process, wrote semistructured interview guides, conducted interviews, designed and prepared the academic workshop and participated in the analysis. TB codesigned the interview guides, conducted interviews and participated in the analysis. ET contributed to the study design, wrote guidelines, consent forms and information leaflets, selected and recruited interviewees.
Funding This research received no specific grant from any funding agency in the public, commercial or not-for-profit sectors.

Competing interests SHM has supported UCL Partners in a remunerated capacity with some of its work on developing an integrated cancer system.

Ethics approval The study was granted ethics approval by London-Queen Square (Formally known as Central London REC 3). The reference number is 10/H0716/66. All participants gave informed consent before participating.

Provenance and peer review Not commissioned; externally peer reviewed.

Data sharing statement Interview transcripts can be accessed by emailing anna@shm-Itd.co.uk.

Open Access This is an Open Access article distributed in accordance with the Creative Commons Attribution Non Commercial (CC BY-NC 4.0) license, which permits others to distribute, remix, adapt, build upon this work noncommercially, and license their derivative works on different terms, provided the original work is properly cited and the use is non-commercial. See: http:// creativecommons.org/licenses/by-nc/4.0/

\section{REFERENCES}

1. NHS England. National Cancer Patient Experience Survey 2012-13 National Report. London: NHS England, 2013.

2. Department of Health. Improving outcomes: a strategy for cancer London: Department of Health, 2010. http://www.dh.gov.uk/ publications

3. Cripe LD. Foreword. The discovered story: the evolution of the truth in cancer narratives. Lit Med 2009;28:vi-x.

4. Hyden LC. Illness and narrative. Sociol Health IIIn 1997;19:48-69.

5. Bury M. IIIness narratives: fact or fiction? Sociol Health IIIn 2001;23:263-28.

6. Frank AW. Tricksters and truthtellers: narrative illness in an age of authenticity and appropriation. Lit Med 2009;28:186-99.

7. Evans MA, Shaw A, Sharp D. Integrity in patients' stories: 'meaning-making' through narrative in supportive cancer care. Eur $J$ Integr Med 2012;4:e11-18.

8. Charon R. Narrative medicine: form, function, and ethics. Ann Intern Med 2001;134:83-7.

9. Greenhalgh T, Hurwitz B, Skultans V. Narrative based medicine. Why study narrative? BMJ 1999;318:48-50.

10. Charmaz K. Loss of self: a fundamental form of suffering in the chronically ill. Sociol Health IIIn 1983;5:168-95.

11. Kahane DH. No less a woman: femininity, sexuality \& breast cancer. Hunter House, 1995.

12. Brookes T. Catching my breath: an asthmatic explores his illness. New York: Times Books, 1994

13. Mairs N. On being a cripple. In: Saxton M, Howe F, eds. With wings: an anthology of literature by and about women with disabilities. New York: The Feminist Press, 1987:118-27.

14. Frank AW. Illness as moral occasion: restoring agency to ill people. Health, 1997;1:131-48.

15. Bate $\mathrm{P}$, Robert $\mathrm{G}$. Experience-based design: from redesigning the system around the patient to co-designing services with the patient Qual Saf Health Care 2006;15:307-10.

16. Bishop FL, Yardley L. Constructing agency in treatment decisions: negotiating responsibility in cancer. Health 2004;8:465-82.

17. Charles C, Gafnia A, Whelan T. Decision-making in the physicianpatient encounter: revisiting the shared treatment decision-making model. Soc Sci Med 1999;49:651-61.

18. Heidegger M. Being and time: a translation of Sein und Zeit. SUNY Press, 1996.

19. Mishler EG. The discourse of medicine. The dialectics of medical interviews. Norwood, NJ: Ablex, 1984. 